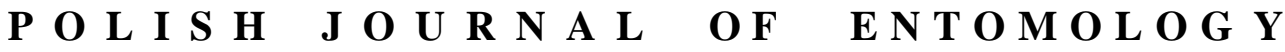

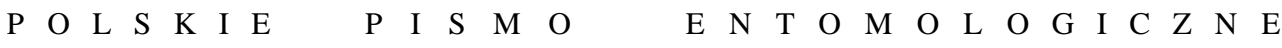

VOL. 86: 181-191

Lublin

30 June 2017

DOI: $10.1515 /$ pjen-2017-0012

\section{Redescription of Erythmelus dichromocnemus NOVICKY, 1953 stat. rev. (Hymenoptera, Mymaridae) and a new synonymy}

\author{
SERGUEI V. TRIAPITSYN ${ }^{1 *}$, VladimiR V. BEREZOVSKIY ${ }^{1}$, \\ PAWEL JAŁOSZYŃSKI ${ }^{2}$ \\ ${ }^{1}$ Entomology Research Museum, Department of Entomology, University of California, \\ Riverside, CA, 92521, USA \\ ${ }^{2}$ Museum of Natural History, University of Wrocław, Sienkiewicza 21, 50-335 Wrocław, \\ Poland
}

\begin{abstract}
Erythmelus (Erythmelus) dichromocnemus NOVICKY, 1953 stat. rev. (Hymenoptera, Mymaridae) is removed from its previous synonymy under E. (Erythmelus) flavovarius (WALKER, 1846), reinstated as a valid name, and redescribed. Its morphological structures are illustrated, and a lectotype is designated based on a syntype female collected in Warsaw, Poland. Erythmelus (Erythmelellus) lygivorus VIGGIANI \& JESU, 1985 syn. n. is placed as a junior synonym under $E$. dichromocnemus. Specimens of E. (Erythmelus) agilis (ENOCK, 1909), E. dichromocnemus, E. flavovarius, E. (Parallelaptera) panis (ENOCK, 1909) and Litus cynipseus HALIDAY, 1833 in the Svatoslav NovickY (Światosław NOwICKI) collection of Mymaridae in Portici, Italy were remounted in Canada balsam from the dried and often darkened original water-soluble mountant medium to prevent further deterioration, and their distribution data are given.
\end{abstract}

KEY WORDS: Taxonomy, Chalcidoidea, fairyfly, synonymy, Poland.

\section{INTRODUCTION}

Forest Engineer Svatoslav NovicKY (Światosław NOwICKI) was a Polish (later in life he lived in Austria), mainly amateur, taxonomist who worked on several families of Chalcidoidea (Hymenoptera) and published a few articles on Mymaridae, or fairyflies (NOVICKY 1953, 1965) in which he described several species from Europe. The remains of

\footnotetext{
* corresponding author: serguei.triapitsyn@ucr.edu
} 
his collection of Mymaridae, most of which he had given to Walter SOYKA (NOVICKY 1953) and are currently deposited in the Naturhistorisches Museum Wien, Vienna, Austria, were donated by him to Gennaro VIGGIANI (VIGGIANI 2011). Most specimens were collected by S. NOviCKY himself during his extensive travels, surprisingly even during World War II. Unfortunately, as described by VIGGIANI (2011) and TRIAPITSYN et al. (2013), his collection of Chalcidoidea is in very poor condition; almost every specimen (or sometimes several specimens) was (were) dipped in liquid Faure (or Hoyer's) medium and either placed between two coverslips or mounted on one coverslip, thus making a very small "slide" that was glued over a circular hole on a card (Fig. 1). The card also served as a primary data label and in some cases as an identification label. All NOVICKY's labels are difficult (often impossible) to read because of his illegible handwriting and frequent omissions of critical data. Over time, the mounting medium on most of these "micro-slides" darkened and dried out to the point that the specimens had become badly fragmented (ruptured by the drying and shrinking water-soluble mounting medium). Specimens were mostly impossible to see and required remounting in Canada balsam in accordance with modern standards (VIGGiani 2011) for proper examination. Prior to this study, only specimens of Cleruchus ENOCK, 1909 from the S. NOVICKY fairyfly collection were remounted and reviewed (TRIAPITSYN et al. 2013).

Here we report on the results of studying NOviCKY's other remounted specimens of Mymaridae, all in Erythmelus ENOCK, 1909 and Litus HALIDAY, 1833, which were kindly made available to the first author by Gennaro VIGGIANI. Among them, the type series (represented by syntypes) of Erythmelus dichromocnemus NoviCKY, 1953 was of particular interest because it had not been examined by taxonomists of Mymaridae since its original description (NOVICKY 1953). TRIAPITSYN (2003) previously synonymized $E$. dichromocnemus under E. (Erythmelus) flavovarius (WALKER, 1846) based solely on the poor original description of the former taxon, because at that time the whereabouts of its type specimens were unknown and they were presumed lost. Discovery and examination of this material by the first author in 2012 helped to clarify the status of this enigmatic species, and revealed a new case of synonymy.

\section{ACKNOWLEDGEMENTS}

The first author thanks Gennaro VIGGIANI (DEZA) and also Martti KoPONEN and Juho PAUKKUNEN (FMNH) for the loans of specimens; the third author thanks Rafat RUTA (University of Wrocław) for making his photographic equipment available. An anonymous reviewer made useful suggestions towards the improvement of the manuscript. 


\section{METHODS AND MATERIAL}

Morphological terminology mostly follows GIBSON (1997). Abbreviations used are: F, funicle segment; mps, multiporous plate sensillum or sensilla on the antennal flagellar segments (= longitudinal sensillum or sensilla or sensory ridge(s) of other publications and authors). The photos in Figs 2-5 and 7-9 were taken at UCRC from slide-mounted specimens using a Zeiss Axioskop 2 plus compound microscope and an Auto-Montage system by Syncroscopy; digital images were processed using Adobe Photoshop; photos 1011 were taken with a KYF75U digital camera (JVC, Yokohama, Japan) mounted on a Leica M205C stereomicroscope; and photos in Figs 12-14 with a Nikon D5100 camera mounted on a Nikon Eclipse Ni compound microscope and a Helicon Focus 6.3.5 Pro system by HeliconSoft.

The studied material is preserved in the Entomological Collection of Dipartimento di Entomologia e Zoologia Agraria «Filippo SILVESTRI», Università degli Studi di Napoli «Federico II», Portici, Italy (DEZA); Zoological Museum, Finnish Museum of Natural History, University of Helsinki, Helsinki, Finland (FMNH); Museum of Natural History, University of Wrocław, Wrocław, Poland (MNHW); and Entomology Research Museum, University of California, Riverside, California, USA (UCRC).

\section{RESULTS}

\section{Erythmelus (Erythmelus) dichromocnemus NOVICKY, 1953, stat. rev.}

(Figs 1-14)

Erythmelus dichromocnemus NovicKY 1953: 13, figs 1-2 (in the figure captions as "Enaesius dichromocnemus"). Original type localities: Poland (Warsaw), and unspecified localities in Hungary and Lower Austria. Type locality of the lectotype designated here: Warsaw, district Targówek, Poland. Stat. rev. (reinstated as a separate species and removed from previous synonymy with E. (Erythmelus) flavovarius (WALKER, 1846) by TRIAPITSYN 2003: 17).

Erythmelus (Erythmelellus) lygivorus VIGGIANI \& JESU 1985: 487. Type locality: Papiano, Marsciano Commune, Perugia Province, Umbria, Italy. Syn. n.

Erythmelus (Erythmelus) lygivorus VIGGIANI \& JESU: TRIAPITSYN 2003: 7 (key), 29-30 (member of the helopeltidis species group; diagnosis, distribution, host associations, illustrations); DONEV 2004: 121 (diagnosis, distribution); PRICOP 2008: 38 (distribution, taxonomic notes), 42, 45 (illustrations); PRICOP 2009a: 73, 75 (list, distribution); PRICOP 


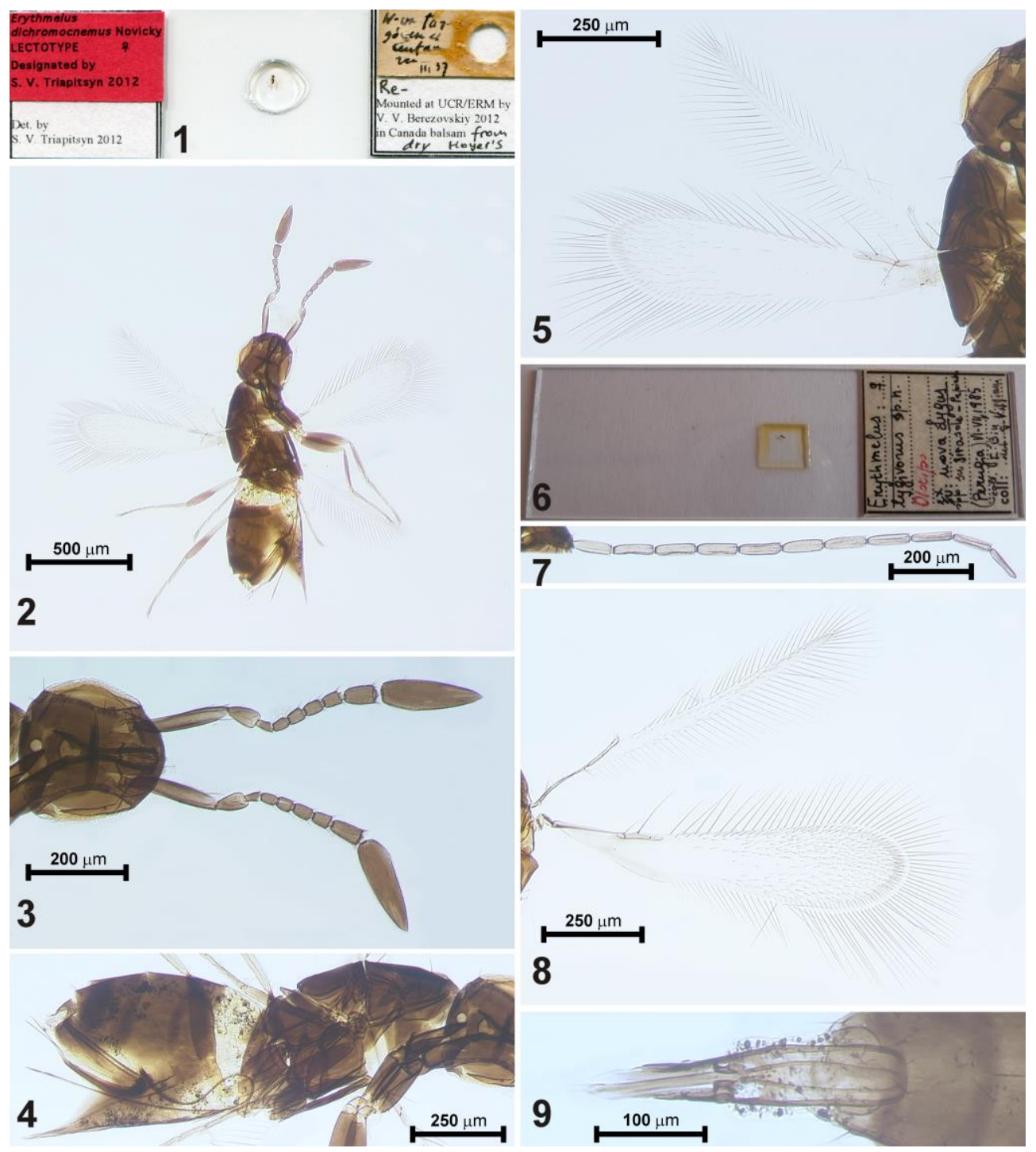

Figs 1-9. Erythmelus dichromocnemus, lectotype female (1-5), holotype of E. lygivorus (6), and male paralectotype of E. dichromocnemus (7-9). Microscope slide of lectotype (original label in the upper right corner) (1); habitus (2); head and antennae in dorsal view (3); mesosoma and metasoma in lateral view (4); fore wing and hind wing (5); holotype slide (6); antenna in lateral view (7); fore wing and hind wing (8); genitalia in dorsal view (9). 


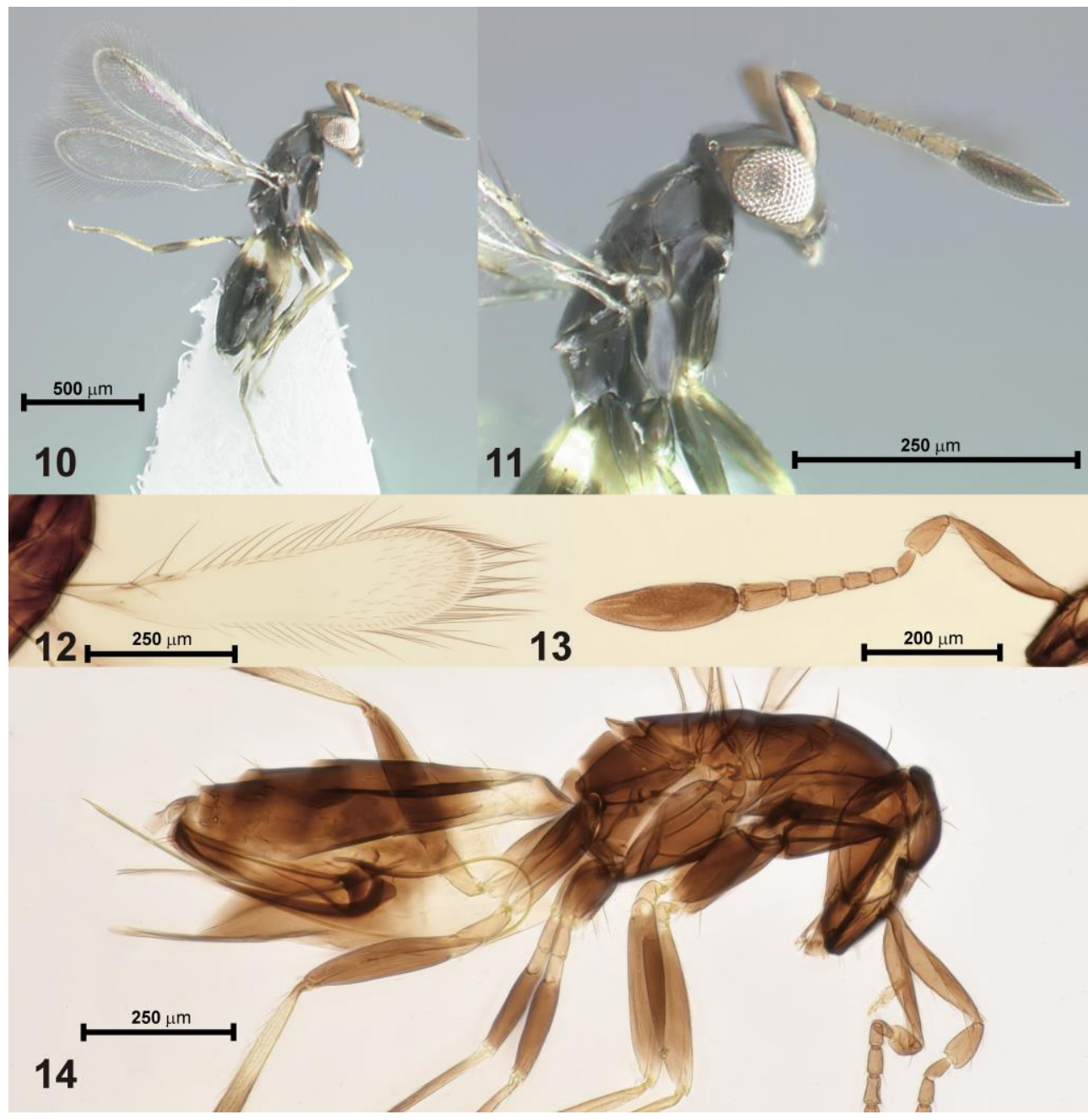

Figs 10-14. Erythmelus dichromocnemus, female (Wrocław Świniary, Poland). Lateral habitus of dry-mounted specimen (10) and enlarged head and mesosoma (11); fore wing (12); antenna in lateral view (13); body in transparent slide, lateral view (14).

2010: 81-82 (list, distribution); Li et al. 2011: 1 (key), 4-5 (redescription, illustrations, distribution), 6 (abstract in Chinese); MANICKAVASAGAM et al. 2012: 394 (distribution), 395 (key), 403 (illustrations); HU \& TRIAPITSYN 2013: 424 (key), 425 (illustration), 427-428 (records from Xinjiang, China; distribution).

Erythmelus lygivorus VIGGIANI \& JESU: PRICOP 2009b: 125 (list). 


\section{Type material examined}

The lectotype female of E. dichromocnemus (DEZA), here designated to avoid confusion regarding the status of the type specimens of this taxon, was selected from a series of syntypes remounted by the second author at UCRC in January 2012 from a dried water-soluble mountant on the original S. NOVICKY-style individual micro-slides on pins (VIGGIANI 2011). The lectotype is in Canada balsam on a microscope slide (Fig. 1) with four labels: "W-wa [i.e., Warszawa] Targówek ex Centaurea III 37" [the original label on the card "micro-slide", handwritten in Indian ink], "Re-Mounted at UCR/ERM by V. V. BEREZOVSKIY 2012 in Canada balsam from dry Hoyer's" [white, printed and handwritten], "Erythmelus dichromocnemus Novicky LECTOTYPE $q$ Designated by S. V. Triapitsyn 2012" [red, printed], "Det. by S. V. TRIAPITSYN 2012" [white, printed]. The lectotype (Fig. 2 ) is in good condition, complete, mounted laterally. Paralectotypes: 7 females and 5 males on individual slides (6 females, 4 males, DEZA; 1 female, 1 male, UCRC), same label data as the lectotype (the label of one female among them is mostly illegible except for the date), and 5 fragmented females plus a gaster of another female (DEZA) on the same slide with the identical label data; 2 fragmented females (DEZA) under the same coverslip on a slide with two labels: "Stara [followed by two illegible words indicating the precise locality, the first word definitely a part of the locality name beginning with "Stara", almost certainly in Poland] 12.6.42 Erythmelus dichromocnemus $\% "$ [the original label on the card "microslide", in pencil], "Erythmelus dichromocnemus" [the original label in Indian ink, on a piece of paper in which the broken "micro-slide" was wrapped]; 1 female (DEZA) on a slide with one label: "[two illegible words (the second word ending with "ö"), the collecting locality may thus have been in Hungary] 3-4.8.40 Erythmelus dichromocnemus क" [the original label on the card "micro-slide", in Indian ink]; and also possibly 1 female (DEZA) on a slide with one label: "Hainburg [i.e., Hainburg an der Donau, Lower Austria] [an illegible word follows, probably indicating the precise locality] 1.8.53 [an illegible word follows] Erythmelus dichromoc. o" [the original label on the card "micro-slide", in Indian ink]. The last-mentioned specimen is only tentatively considered to be a paralectotype because, although NOVICKY (1953) mentioned this species from Lower Austria, it was collected in August 1953 whereas the description of E. dichromocnemus was published in the January-February (number 1/2) issue of the journal for the year 1953; however, the information relating to it could have been included in NOVICKY's paper if this issue had been printed and mailed later that year (we were unable to determine that date).

Holotype female of E. (Erythmelellus) lygivorus (DEZA) on slide (Fig. 6) labelled: "Erythmelus + lygivorus sp. n. Olotipo [in red ink] su: [crossed out] ex uova Lygus spp. su girasole - Papiano (Perugia) VI-VII, 1985 coll. F. Bin coll: det. G. Viggiani”. The holotype is in good condition, complete, mounted dorsoventrally. Paratypes of this species are also in DEZA, as listed by VIGGIANI \& JESU (1985). 


\section{Other specimens examined}

Finland: Tavastia Proper, Hämeenlinna (Lammi), 27.viii.1984, M. KoPONEN (1 female, FMNH). Italy: Campania: Benevento Prov., $1.8 \mathrm{~km}$ E of Faicchio, $41^{\circ} 16.329^{\prime} \mathrm{N}$ 14²9.884'E, 210 m, 7.vi.2003, M. Bologna, J. Munro, A. Owen, J.D. Pinto (1 female, UCRC); Napoli Prov., Portici, Parco Gussone (oakwood), 3-4.vi.2003, J. MunRo, A. Owen, J.D. PINTo (1 female, UCRC). Lazio, Roma Prov., Castelporziano Presidential Estate: La Focetta, $41^{\circ} 41.474^{\prime} \mathrm{N} 12^{\circ} 22.633^{\prime} \mathrm{E}, 10 \mathrm{~m}, 11-12 . v i .2003$, J. MUNRO, A. OwEN (2

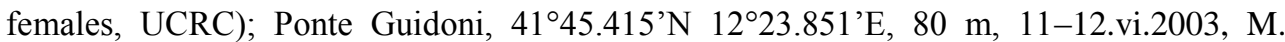
Bologna, J. Munro, A. Owen, J.D. PInto (17 females, 1 male, UCRC). Poland: Lower Silesia, Wrocław Świniary, 20.viii.2016, P. JAŁOSZYŃSKI (reared from dry flowerheads of Centaurea stoebe L., adults emerged end of August 2016) (2 females, MNHW). Russia: Stavropol'skiy Kray, NW of Kislovodsk, 4355'30'” 42² '53'”E, 810 m, 29.v.2003, E.V. KHOMCHENKO (1 female, UCRC).

\section{Diagnosis}

The following unique combination of morphological features separates females of $E$. dichromocnemus from females of all other members of the helopeltidis species group of Erythmelus (Erythmelus), as defined by TRIAPITSYN (2003): antenna (Figs 3, 11, 13) with all funicle segments longer than wide, F1-F5 each notably shorter than F6, and only F6 with mps; fore wing (Figs 5,12) $4.1-4.2 \times$ as long as wide, its disc more or less evenly setose only in about apical three-tenths; gastral tergum 1 contrastingly brown basally and yellow or light brown distally (Fig. 11); ovipositor (Figs 4, 14) approximately 2.5-3.1× metatibia length (if the entire length of ovipositor is measured including base of the loop).

As noted by TRIAPITSYN (2003) for E. lygivorus, specimens of E. dichromocnemus, particularly the uncleared, dry-mounted females, may be confused with females of $E$. flavovarius with a darker mesoscutum, as both species have similar antennae. However, the fore wing disc of E. dichromocnemus has a relatively larger bare area (Figs 5, 12) in the female and its ovipositor has a large basal loop (Figs 4, 14), which is more evident in cleared specimens.

\section{Redescription}

Female (Figs 2-5, 10-14, redescription based on lectotype and paralectotypes of $E$. dichromocnemus). Body length 1076-1235 $\mu \mathrm{m}$. Body largely dark brown to nearly black, except base of gaster yellow or light brown (first gastral tergum contrastingly brown basally and yellow or light brown distally, Fig. 11), hypopygium brown, and midlobe of mesoscutum with at least a little lighter (yellow to light brown or brown) transverse submedian stripe. Antenna brown with scape pale brown or yellowish along ventral margin, pedicel indistinctly lighter than funicle, clava darkened. Legs largely brown to nearly black 
except metacoxa apically, trochanters, sometimes entire protibia, about basal half of metatibia, and tarsi light brown or pale yellowish.

Antenna (Figs 3, 11, 13) with scape 5.4-5.5× as long as wide; pedicel much longer than F1; all funicle segments longer than wide; F1-F3 the shortest funicle segments, F4 and F5 a little longer, and F6 the longest funicle segment; F1-F5 lacking mps, F6 with two mps; clava $3.2-3.5 \times$ as long as wide, with five mps.

Mesosoma (Figs 4, 14). Midlobe of mesoscutum finely longitudinally striate, adnotaular setae robust. Axillar seta robust. Frenum finely longitudinally striate.

Wings (Figs 5, 10, 12). Fore wing $4.1-4.2 \times$ as long as wide; disc slightly infumate behind submarginal vein and at apex, otherwise hyaline, with more or less evenly distributed setae only in about apical three-tenths; longest marginal seta about $1.1 \times$ greatest width of wing. Hind wing about $15 \times$ as long as wide, about as long as fore wing; apical (about one third) part of disc infumate; the longest marginal seta $3.5 \times$ greatest width of wing.

Metasoma (Figs 4, 14). Gaster longer than mesosoma; ovipositor with a large basal loop, occupying most of gaster length in repose, but often markedly exserted beyond apex of hypopygium (up to one third of own length beyond apical gastral tergum, depending on the size and configuration of its basal loop: the shorter the latter is, the more the ovipositor is exserted), and approximately $2.5-3.1 \times$ length of metatibia (if entire length of ovipositor is measured including base of loop).

Lectotype measurements $(\mu \mathrm{m})$. Body length 1248; length of head (as mounted) 283; length of mesosoma 467; length of petiole 15; length of gaster 590; length of ovipositor (approximately, including the loop) 840. Antenna (all lengths): scape 185; pedicel 63; F1 30; F2 31; F3 30; F4 36; F5 36; F6 60; clava 194. Fore wing length 806, width 196; longest marginal seta length 216 . Hind wing length 800 , width 54 ; longest marginal seta length 190.

Male (Figs 7-9, redescription based on paralectotypes of E. dichromocnemus). Body length 1140-1240 $\mu \mathrm{m}$. Similar to female except as follows. Antenna (Fig. 7) uniformly brownish, with scape about $1.7 \times$ as long as wide; all flagellomeres much longer than wide and longer than pedicel. Wings (Fig. 8) slightly infumate; fore wing 3.9-4.1× as long as wide, with disc more pubescent than in female (about apical half of the wing setose). Genitalia (Fig. 9) length about $300 \mu \mathrm{m}$.

\section{Distribution}

Austria, Hungary and Poland (NOvicKY 1953), as well as France, Italy and Spain (TRIAPITSYN 2003, as E. lygivorus), Bulgaria (DONEV 2004, as E. lygivorus), China (LI et al. 2011; HU \& TRIAPITSYN 2013, as E. lygivorus), Finland (new record), India 
(MANICKAVASAGAM et al. 2012, as E. lygivorus), Romania (PRICOP 2008, as E. lygivorus), and Russia (new record).

\section{Hosts}

Lygus pratensis (LinNAEUS, 1758) and L. rugulipennis PoPPIUS, 1911 (Hemiptera, Miridae) (VIgGiani \& Jesu 1985); also Lygus spp. (Viggiani \& Jesu 1988). Novicky (1953) noted that E. dichromocnemus was definitely an egg parasitoid of (true) bug eggs because when he had reared a large series of both sexes of this species in March 1935 (?1937) from straw of Centaurea sp. in Warsaw, red nymphs of a (true) bug with a black head and thorax emerged together with the parasitoids. Indeed, one of his "micro-slides" with the same label as the lectotype of E. dichromocnemus contains a bug nymph which, however, is definitely not a mirid but rather a member of Pentatomomorpha (C. WEIRAUCH and D. YANEGA, personal communications, UCRC). However, this is only a presumed, by no means proven, host-parasitoid association.

\section{Lectotype designation}

NOviCKY (1953) did not designate any type(s), and therefore all type specimens have the status of syntypes. The female (Figs 1-5) is here designated as a lectotype.

\section{Remarks}

NOVICKY (1953) gave the following information on the specimens he used to describe E. dichromocnemus (p. 13), as translated from German: "Poland, Hungary, Lower Austria, in the middle of summer. In Warsaw a large series of both sexes was reared in March 1935 from straw of Centaurea". However, the correct collecting date is probably indicated on all the labels of the syntypes from Warsaw: March 1937; the collection locality was Targówek, a district in Warsaw located east of the River Wisła (Vistula).

Two females of E. dichromocnemus (Figs 10-14) were recently reared by the third author from dry flowerheads of Centaurea stoebe L. (Asteraceae) collected from a xerothermic locality near Wrocław, Poland. Interestingly, the lectotype of $E$. dichromocnemus was also collected in Poland from the same plant genus (NOVICKY 1953).

\section{LIST OF OTHER REMOUNTED AND IDENTIFIED MYMARIDAE OF S. NOVICKY IN DEZA}

\section{Erythmelus (Erythmelus) agilis (Enock, 1909)}

Poland: Province of Mazovia, "E.K.D." (specimens were collected by S. NOvICKY using an aspirator on window panes in carriages of the electric railway from Warsaw to 
Grodzisk Mazowiecki), 16.viii.1939, S. NovickY (1 female). Locality unclear (illegible handwriting, probably in Poland): 5.vii.1942, S. NOviCKY (1 female); 16.vii.1943, S. NOVICKY (1 female).

\section{Erythmelus (Erythmelus) flavovarius (WALKER, 1846)}

Austria: Vienna, Vienna: Leopoldstadt, 27.vii.1946, S. NOVICKY (1 female); 28.vii.1946, S. NovicKY (1 male). Poland: Masovian Voivodeship: ?Grodzisk Mazowiecki (a guess - the handwriting is illegible), ?25.viii.1937, S. NoviCKY (2 females). ?Grójec (a guess - the handwriting is illegible), 25.viii.1937, S. NovicKY (1 female). Warsaw, "E.K.D." (specimens were collected by S. NOVICKY using an aspirator on window panes in carriages of the electric railway from Warsaw to Grodzisk Mazowiecki): 25.viii.1937 (1 female); 7.ix.1937 (1 female). Locality unclear (handwriting illegible): ?16.vi.1934, S. NOVICKY (4 females); 11.viii.1935, S. NOVICKY (1 female).

\section{Erythmelus (Parallelaptera) panis (ENOCK, 1909)}

Hungary: Budapest: 8.vii.1937, S. NOvicKY (1 female); 9.vii.1937, S. NOviCKY (1 male).

\section{Litus cynipseus HALIDAY, 1833}

Poland: Province of Małopolska, Babica, 14.ix.1935, S. Novicky (1 female). Province of Łódź, Skierniewice, 1920s, S. NOVICKY (1 female). Locality unclear (illegible handwriting on the label), vii.1941 (1 female).

\section{REFERENCES}

Donev A.D. 2004. The species of Erythmelus Enock, 1909 (Hymenoptera, Mimaridae [sic]) in the Balkan Peninsula. Plovdivski Universitet "Paisiy Hilendarski", Nauchni Trudove, Biologiya Animalia 40(6): 119-127.

GibSON G.A.P. 1997. Chapter 2. Morphology and terminology. [in:] G.A.P. GiBSON, J.T. HubER, J.B. Woolley (eds.). Annotated keys to the genera of Nearctic Chalcidoidea (Hymenoptera). NRC Research Press, Ottawa, Ontario, Canada, 16-44.

Hu H., Triapitsyn S.V. 2013. Taxonomic notes on Erythmelus EnOCK (Hymenoptera: Mymaridae) from Xinjiang, China, with description of a new species. Turkish Journal of Zoology 37(4): 423-430.

Li X., LIN N.-Q., HU H.-Y. 2011. Description of two new species and one newly recorded species of the genus Erythmelus ENOCK (Hymenoptera, Mymaridae) from Xinjiang. Acta Zootaxonomica Sinica 35(3): 1-6. 
MANickAVASAgAm S., RAMEShKuMAR A., RAJMOHANA K. 2012 (2011). First report of four species of fairyflies from India, key to Indian species of four genera and additional distributional records of Mymaridae (Hymenoptera: Chalcidoidea). The Madras Agricultural Journal 8(10-12): 393-408.

NOVICKY S. 1953. Vorläufige Beschreibung einiger Mymariden. (Hymenoptera, Chalcidoidea), I. Teil. Entomologisches Nachrichtenblatt Österreichischer und Schweizer Entomologen 5(1/2): $13-15$.

NOvicky S. 1965. Übersicht der Arten der Gruppe Cleruchus EnOcK (Chalc., Mymar.) mit Beschreibungen neuer Arten aus Europa. Zeitschrift für Angewandte Entomologie 56(1-4): $56-60$.

PRICOP E. 2008. Mymarid wasps (Hymenopetra, Chalcidoidea, Mymaridae) new to Romanian fauna. Analele Ştiinţifice ale Universităţii "Alexandru Ioan Cuza" din Iaşi (serie nouă), Secţiunea I, Biologie Animală 54: 35-48.

PRICOP E.I. 2009a (2007-2008). Mymarid wasps (Hymenoptera, Chalcidoidea, fam. Mymaridae) associated with Medicago sativa L. (first note). Studii şi Comunicări, Complexul Museal de Ştiinţele Naturii “Ion Borcea” Bacău 22: 72-77.

PRICOP E. 2009b (2008). A faunistic review of the Romanian Mymaridae and Mymarommatidae (Hymenoptera Chalcidoidea and Mymarommatoidea). Analele Ştiinţifice ale Universităţii "Alexandru Ioan Cuza"din Iaşi (serie nouă), Secţiunea I, Biologie Animală, Supliment. Lucrările Simpozionului „Entomofagii şi rolul lor în păstrarea echilibrului natural”, Agigea-Constanţa, [6-8 June 2008]. Editura Universitatii „Alexandru Ioan Cuza” Iaşi, 121-128.

PrICOP E. 2010 (2009). Mymarid wasps (Hymenoptera, Chalcidoidea, fam. Mymaridae) associated with Medicago sativa L. (first note). Studii şi Cercetări Ştiinţifice, Seria Biologie, Universitatea "Vasile Alecsandri” din Bacău 17: 80-85.

TRIAPITSYN S.V. 2003. Review of the Mymaridae (Hymenoptera, Chalcidoidea) of Primorskii krai: genus Erythmelus ENOCK, with taxonomic notes on some extralimital species. Far Eastern Entomologist 126: 1-44.

TRIAPITSYN S.V., Berezovskiy V.V., Viggiani G. 2013. Taxonomic notes on three little-known species of Cleruchus ENOCK (Hymenoptera: Mymaridae) described by S. NovicKY from Europe. North-Western Journal of Zoology 9(1): 6-15.

VIGGiANI G. 2011 (2009). Notes on the collection of Mymaridae and Trichogrammatidae (Hymenoptera: Chalcidoidea) of S. NowICKI and on some Aphelinoidea (Hymenoptera: Trichogrammatidae). Note sulla collezione di Mymaridae e Trichogrammatidae (Hymenoptera: Chalcidoidea) di S. NOwICKI e su alcuni Aphelinoidea (Hymenoptera: Trichogrammatidae). Frustula Entomologica (n. s.) 32(45): 101-110.

VigGiAni G., JESU R. 1985. Due nuove specie paleartiche del genere Erythmelus ENOCK (Hymenoptera: Mymaridae). Redia 68: 485-491.

VIgGIANI G., Jesu R. 1988. Considerazioni sui Mimaridi italiani ed i loro ospiti. Atti [XV] Congresso Nazionale Italiano di Entomologia (L'Aquila) 15: 1019-1029.

Received: 8 May 2017

Accepted: 29 May 2017 